\title{
Measurements of the total ozone column using a Brewer spectrophotometer and TOMS and OMI satellite instruments over the Southern Space Observatory in Brazil
}

\author{
Lucas Vaz Peres ${ }^{1,2}$, Hassan Bencherif ${ }^{3,4}$, Nkanyiso Mbatha ${ }^{5}$, André Passaglia Schuch ${ }^{1}$, \\ Abdoulwahab Mohamed Toihir ${ }^{3}$, Nelson Bègue ${ }^{3}$, Thierry Portafaix ${ }^{3}$, Vagner Anabor ${ }^{1}$, Damaris Kirsch Pinheiro ${ }^{1}$, \\ Neusa Maria Paes Leme ${ }^{6}$, José Valentin Bageston ${ }^{7}$, and Nelson Jorge Schuch ${ }^{7}$ \\ ${ }^{1}$ Federal University of Santa Maria, Santa Maria - RS 97195-000, Brazil \\ ${ }^{2}$ CAPES Foundation, Ministry of Education of Brazil, Brasília - DF 70040-020, Brazil \\ ${ }^{3}$ University of Reunion Island, LACy, UMR 8105, Réunion, France \\ ${ }^{4}$ University of KwaZulu-Natal, School of Chemistry and Physics, Durban, South Africa \\ ${ }^{5}$ University of ZuluLand, Department of Geography, KwaDlangezwa, 3886, South Africa \\ ${ }^{6}$ Northern Regional Center, National Institute for Space Research - CRN/INPE, Natal - RN, 59076-740, Brazil \\ ${ }^{7}$ Southern Regional Center, National Institute for Space Research - CRS/INPE, Santa Maria - RS, 97105-970, Brazil
}

Correspondence to: Lucas Vaz Peres (lucasvazperes@gmail.com)

Received: 7 May 2016 - Revised: 4 November 2016 - Accepted: 14 November 2016 - Published: 3 January 2017

\begin{abstract}
This paper presents 23 years (1992-2014) of quasi-continuous measurements of the total ozone column (TOC) over the Southern Space Observatory (SSO) in São Martinho da Serra, Brazil $\left(29.26^{\circ} \mathrm{S}, 53.48^{\circ}\right.$ and $488 \mathrm{~m}$ altitude). The TOC was measured by a Brewer spectrometer, and the results are also compared to daily and monthly observations from the TOMS (Total Ozone Mapping Spectrometer) and OMI (Ozone Monitoring Instrument) satellite instruments. Analyses of the main interannual modes of variability computed using the wavelet transform method were performed. A favorable agreement between the Brewer spectrophotometer and satellite datasets was found. The seasonal TOC variation is dominated by an annual cycle, with a minimum of approximately $260 \mathrm{DU}$ in April and a maximum of approximately 295 DU in September. The wavelet analysis applied in the SSO TOC anomaly time series revealed that the Quasi-Biennial Oscillation (QBO) modulation was the main mode of interannual variability. The comparison between the SSO TOC anomaly time series with the QBO index revealed that the two are in opposite phases.
\end{abstract}

Keywords. Atmospheric composition and structure (middle atmosphere - composition and chemistry)

\section{Introduction}

Measurements of total ozone columns (TOCs) have been made around the world by ground-based Dobson spectrophotometer instruments since the 1930s (Dobson, 1930, 1968); recently, more modern automated instruments such as Brewer (Kerr et al., 1985; Kerr, 2002) and SAOZ (Pommereau and Goutail, 1988) spectrophotometers have also been used. Additional techniques such as Fourier transform infrared spectroscopy (FTIR) (Hase et al., 1999), Lidar (Baray et al., 1999), and radiosonde (Thompson et al., 2003) measurements have complemented the continuous record.

Despite the significant increase in high-quality groundbased TOC measurements in recent decades, the monitoring network remains limited in terms of spatial and temporal coverage. Satellite measurements have been providing a better continuous geographical distribution. These measurements require validation against ground-based measurements for the verification of their accuracy (WMO, 1996, 2003) and to develop correction algorithms where necessary (Bhartia and Wellemeyer, 2002).

Ozone monitoring through ground-based instruments and comparison with data from satellites for midlatitude regions (Balis et al., 2007; McPeters et al., 1998; Keckhut et al., 2010) is essential because, in these densely populated re- 
gions, phenomena occur such as the formation of mini ozone holes in the Northern Hemisphere (Semane et al., 2002) and events that influence the Antarctic ozone hole (Farman et al., 1985; Solomon, 1999) in the Southern Hemisphere (Kirchhoff et al., 1996; Perez et al., 1998; De Laat et al., 2010; Pinheiro et al., 2012; Schuch et al., 2015). Ozone content exchange between the stratosphere and the troposphere (Holton et al., 1995; Stohl et al., 2003) occurs in both hemispheres (Škerlak et al., 2014) at midlatitudes.

A number of studies have been conducted on long-term TOC monitoring to analyze ozone trends and temporal and spatial variations (Stratospheric Processes and Their Role in Climate (SPARC), 1998) using a variety of ground and satellite instruments and their intercomparisons (Reinsel et al., 2002; Antón et al., 2011; Toihir et al., 2015). Such studies have been systematically carried out, resulting in TOC differences of approximately $3 \%$ (Fioletov, 2008; Antón et al., 2009, 2010a; Hendrick et al., 2011).

The equatorial stratosphere is dominated by an oscillating pattern of downward-propagating easterly and westerly zonal wind regimes; this Quasi-Biennial Oscillation (QBO) (Angell and Korshover, 1964) produces temperature anomalies, which in turn modify the Brewer-Dobson circulation. Holton and Lindzen (1972) explained the basic physical mechanisms of the phenomenon, and Baldwin et al. (2001) gave a detailed description of the current understanding of the QBO in wind, temperature, and ozone data.

Wavelet analysis is a powerful tool for investigating the dominant modes of variability and analyzing the localized variations of power within a time series (Torrence and Compo, 1998). It has enabled the investigation of the vertical structure of the stratosphere (Fadnavis and Beig, 2008) and the study of numerous geophysical events (Wang and Wang, 1996; Baliunas et al., 1997).

This study presents measurements of TOC over the Southern Space Observatory (SSO) in southern Brazil. Data have been recorded by a Brewer spectrophotometer quasicontinuously for 23 years (1992 to 2014); these measurements are compared with data from spaceborne satellite sensors (TOMS - OMI). The climatology is derived to determine the seasonal variability in the TOC, and wavelet analysis is used to identify the variability modes and quantify this influence in multidecadal datasets. These analyses are complementary to global- (Fioletov et al., 2002; Hudson et al., 2006) and regional-scale (Rigozo et al., 2012) studies of TOC variability and contribute to the understanding of the seasonal and interannual ozone variability over southern Brazil.

\section{Datasets and methodology}

\subsection{Brewer spectrophotometer and satellite experiments}

Long-term TOCs measured over the Southern Space Observatory by the Brewer spectrophotometer and satellites measurements (TOMS and OMI) are used in this work. The technical and scientific cooperation between the South Regional Center of the National Institute for Space Research (CRS/INPE) and the Federal University of Santa Maria (UFSM) allowed the installation of a Brewer spectrophotometer (MKIV \#081) in June 1992-February 1999, a Brewer spectrophotometer (MKII \#056) in April 2000May 2002, and a Brewer spectrophotometer (MKIII \#167) in July 2002-December 2014 in the Southern Space Observatory in São Martinho da Serra $\left(29.26^{\circ} \mathrm{S}, 53.48^{\circ} \mathrm{W}\right)$.

The Brewer spectrophotometer is a fully automated instrument developed for the ground-based measurements of spectral irradiances of the UV-B part of the solar spectrum at five wavelengths, 306.3, 310.1, 313.5, 316.8, and $320.1 \mathrm{~nm}$, with a $0.5 \mathrm{~nm}$ approximate resolution, allowing for the deduction of the total column of ozone $\left(\mathrm{O}_{3}\right)$, sulfur dioxide $\left(\mathrm{SO}_{2}\right)$, and nitrogen dioxide $\left(\mathrm{NO}_{2}\right)$. It can also obtain the aerosol optical depth in the atmosphere, the average temperature of the ozone layer, and the vertical profile of $\mathrm{O}_{3}$ using the Umkehr technique (Kerr et al., 1985; Kerr, 2002). The Brewer instruments located in the Southern Space Observatory (SSO) belong to the Brazilian Brewer network, and the main standard tests of standard lamp (SL), mercury lamp (Hg), shutter motor run/stop (RS), and photomultiplier dead time (DT) are accompanied daily by a printed summary sheet at the end of each $24 \mathrm{~h}$ period. Furthermore, UV tests with the external lamps are conducted on a monthly basis, while the scan test is performed occasionally in accordance with the manufacturer's recommendations (SCI TEC, 1988). A detailed description of these tests can be found in a study by Vanicek (2003), which shows the calibration history of the Dobson and Brewer instruments in Prague, Czech Republic, that point to the correct function of the Brewer spectrophotometer and consequently the accurate processing of the observations depending on the precise adjustments of the optical, electronic, and mechanical components. This was obtained the adjustment of a large set of technical parameters defined as the instrument calibration constants for each manufacturer instrument, which can be utilized in comparison with a reference (standard) instrument. In South America, the accuracy and quality of data in the TOC is ensured by calibrations with the traveling reference Brewer \#017 (Fioletov et al., 2005), which belongs to International Ozone Services Inc. and provides calibrating services (WMO, 1996).

The TOC monitoring over the south of Brazil is accomplished by formulating the TOC daily average time series obtained by Brewer spectrophotometers using the direct-sun (DS) method on cloud-free days. The Brewer DS analysis 
considered in this study follows criteria similar to that performed by Fioletov et al. (2005), as follows.

The individual DS ozone observations are performed five times in $3 \mathrm{~min}$ for each half hour. The standard deviations of the measured ozone were computed in a group of five individual DS measurements for each wavelength. Data were only considered if the standard deviation was lower than 2.5 DU. To obtain a better statistics analysis, the number of the individual DS data should be at least 35 (about seven sequences of five observations), and only typical clear-sky days at solar zenith angles below $65^{\circ}$ were considered in the calculation of ozone.

The daily ozone measurements by satellite used in this study were obtained through overpass measurements from the Total Ozone Mapping Spectrometer (TOMS), developed by National Aeronautics and Space Administration (NASA), on board the Meteor-3 and Earth Probe satellites and the Ozone Monitoring Instrument (OMI), which is on board the EOS-Aura satellite.

The TOMS instrument started operating in 1978, with the launch of the Nimbus-7 satellite, continuing from 1991 to 1994 aboard the Meteor-3 satellite and since 1996 aboard the Earth Probe, stopping operation in late 2005. The TOMS ozone overpass data used in this work are from the version 8 TOMS algorithm, available on the NASA website http://acdisc.gsfc.nasa.gov/opendap/ (Bhartia and Wellemeyer, 2002; Wellemeyer et al., 1997, 2004). TOMS uses the backscatter ultraviolet (BUV) technique, a measurement method that determines ozone indirectly by mapping the ultraviolet light emitted by the sun and backscattered from the Earth's atmosphere towards the satellite. TOMS provides UV radiation backscattered samples in six wavelengths that suffer differential absorption by ozone. Comparing these measures with the measures from the sun, the TOMS algorithm calculates the TOC (McPeters et al., 1996; Herman et al., 1996).

At the end of 2005, the TOMS equipment ended its mission and was replaced by the Ozone Monitoring Instrument (OMI). This equipment is on board the Aura satellite, which was launched in July 2004 in the framework of Earth Observing System (EOS) mission, and it is currently operational. The OMI instrument measures atmospheric components, such as the total content of $\mathrm{O}_{3}, \mathrm{NO}_{2}, \mathrm{SO}_{2}$, and aerosols, and can be downloaded from the NASA website: http://avdc.gsfc. nasa.gov/index.php? site $=1593048672 \& \mathrm{id}=28$.

Just like TOMS, OMI performs measures through the BUV technique with two images feeding the spectrometer grid. It has two ultraviolet bands, namely the UV-1 270 at $314 \mathrm{~nm}$ and UV-2 306 at $380 \mathrm{~nm}$ with a spectral resolution of 1-0.45 nm (McPeters et al., 1998).

The Brewer daily average measurement used in this analysis is considered satisfactory because the overpass satellite measurements show only one daily value, allowing the comparison between a large number of pair measurements (Antón et al., 2010b).
Figure 1 shows a time series for each instrument groundbased (panel a) and satellite (panel b) used for TOC monitoring over the South Space Observatory (SSO) between 1992 and 2014, noting a well-defined annual cycle in all datasets together with large periods of missing data in the Brewer spectrophotometer dataset between 1999 and 2000 and between 2009 and 2011 and the TOMS satellite dataset between 1994 and 1996. The gap observed between 1999 and 2000 indicates the period of exchanging the Brewer instrument (update \#081 to \#056), while the gap between 2009 and 2011 is due to an electronic problem. The gap observed between 1994 and 1996 in the TOMS satellite data is related to replacing the Meteor-3 and Earth Probe satellite instruments.

\subsection{Comparison analysis}

The TOC daily averaged data from the Brewer instruments were compared with the satellite instrument datasets (TOMS and OMI) to analyze the correspondence between both datasets and to confirm the effectiveness of the long-term Brewer spectrophotometers TOC monitoring over the Southern Space Observatory. Two datasets were used:

Dataset \#1: TOMS - Brewer; June 1992December 2005.

Dataset \#2: OMI - Brewer; October 2004December 2014.

A linear regression analysis was performed for each dataset, and the correlation coefficient $\left(R^{2}\right)$ and the root mean square error (RMSE) between the measurements were calculated. In addition, the mean bias error (MBE) and the mean absolute bias error (MABE) were calculated for all the possible data pairs of each dataset. The RMSE, a measure frequently used to estimate the difference between values predicted by a model (or satellite), and the values observed (in this case a Brewer spectrophotometer), also called residuals, which aggregates them into a single measure of predictive power, were also calculated using the following formula:

$\mathrm{RMSE}=\sqrt{\frac{\sum_{i=1}^{n}\left(\text { Satellite }_{i}-\text { Brewer }_{i}\right)^{2}}{n}}$,

where $n$ is the data pair number. The values of the MBE represent the systematic error or bias. A positive value of $\mathrm{MBE}$ indicates an overestimate, while a negative value indicates underestimation by the model. The MABE gives the absolute bias error value, and it is a measure of the correlation goodness.

The MABE and MBE were also calculated analogically as performed by other authors for comparison studies (e.g., Antón et al., 2009, 2010b; Ialongo et al., 2008; Toihir et al., 2015), and the formulas for these parameters can be repre- 

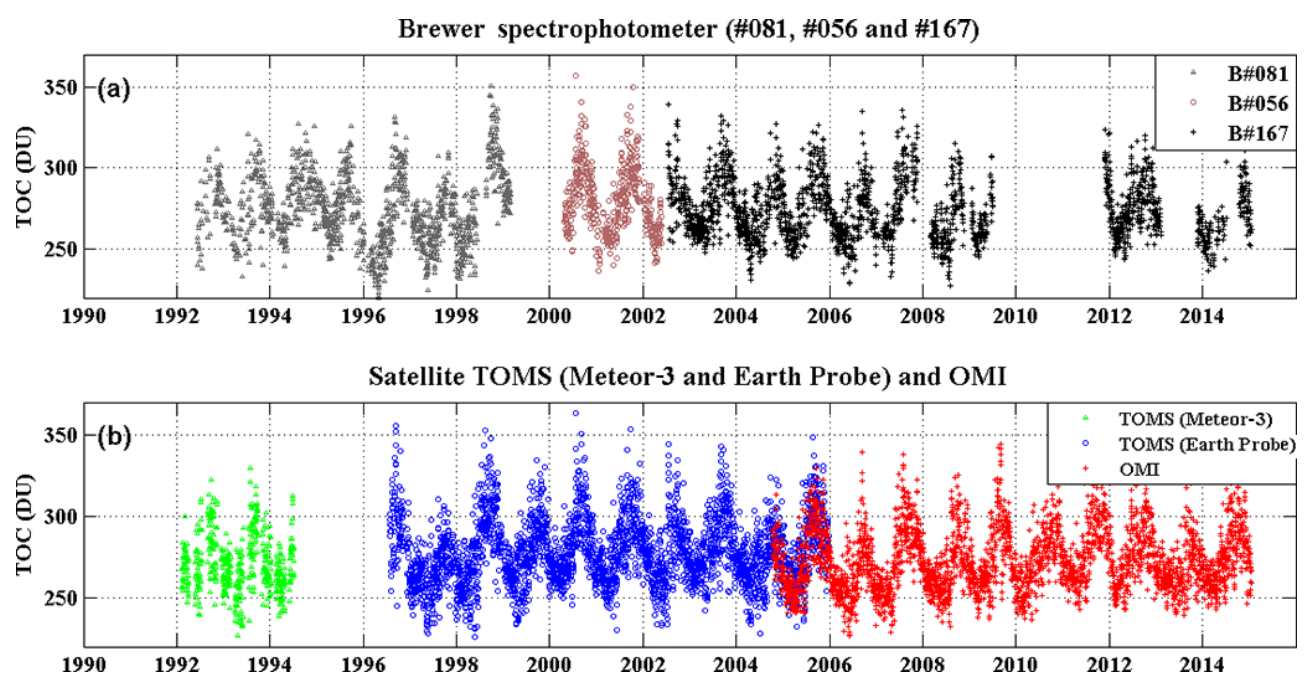

Figure 1. Schematic diagram of the TOC time series for each instrument (Brewer and satellite) at the Southern Space Observatory (SSO) between 1992 and 2014. (a) Brewer spectrophotometer (\#081 in grey triangles, \#056 in brown circles and \#167 in black crosses) and (b) TOMS (Meteor-3 in green triangles and Earth Probe in blue circles) and OMI (in red crosses) satellite instruments.

sented as

$\operatorname{MABE}=\frac{100}{N} \sum_{i=1}^{N} \frac{\mid \text { Satellite }_{i}-\text { Brewer }_{i} \mid}{\text { Brewer }_{i}}$

MBE $=\frac{100}{N} \sum_{i=1}^{N} \frac{\text { Satellite }_{i}-\text { Brewer }_{i}}{\text { Brewer }_{i}}$.

Additionally, a statistical analysis of percent differences (see Eq. 4) computed for each day and also month by month was conducted to verify the accuracy between ground and satellite instruments measures (e.g., Hendrick et al., 2011).

Percent_Difference $=$

$$
100 \cdot\left(\frac{\left(\text { Satellite }_{i}-\text { Brewer }_{i}\right)}{\left(\left(\text { Satellite }_{i}+\text { Brewer }_{i}\right) / 2\right)}\right)
$$

To study the relationship between the QBO and ozone anomalies, the zonal wind at $30 \mathrm{hPa}$ over Singapore was used as a QBO index, and it can be obtained from the NOAA website: http://www.esrl.noaa.gov/psd/data/correlation/qbo.data.

\subsection{Wavelet analysis}

To verify the dominant modes of ozone interannual variability and how these modes vary throughout time, TOC data from Brewer spectrophotometer and satellite instruments recorded over the Southern Space Observatory were analyzed based on the wavelets transform method. The wavelet analysis was described in detail by Torrence and Compo (1998) and is considered a powerful tool for analyzing the localized variations of power spectrum within a time series by decomposing these time series in time-frequency space. The wavelet transform of a discrete data series is defined as the convolution between the series and a scaled and translated version of the chosen wavelet function. FoufoulaGeorgiou and Kumar (1995) described a geophysical application, and Daubechies (1992) described a theoretical treatment of wavelet analysis.

In this work, the deseasonalized Brewer and satellite TOC monthly anomaly time series, obtained by subtracting the monthly mean time series (not shown) from the monthly climatological mean, are applied using the wavelet transform method to reveal the basic modes of interannual ozone variability (Hadjinicolaou et al., 2005). The wavelet transform method chosen is the Morlet one, which consists of a plane wave modulated by a Gaussian function:

$\psi_{0}(\eta)=\pi^{\frac{1}{4}} e^{i \omega_{0} \eta} e^{\frac{-\eta^{2}}{2}}$.

Here, $\omega_{0}$ is the nondimensional frequency, and $\eta$ is nondimensional time parameter. The continuous wavelet transform of a discrete time series $X_{n}$, with equal time spacing $\Delta t$, with $n=0, \ldots, N-1$, is defined as

$W_{n}(s)=\sum_{n^{\prime}=0}^{N-1} x_{n} \psi^{*}\left[\frac{\left(n^{\prime}-n\right) \Delta t}{s}\right]$,

where the $(*)$ indicates the complex conjugate and $s$ indicates the wavelet scale (period).

The global wavelet spectrum was calculated as the timeaveraged wavelet spectrum over a certain period when the average is over all the local wavelet spectra (Torrence and Compo, 1998) and provides an unbiased and consistent estimation of the true power spectrum of a time series Percival (1995):

$\overline{W^{2}}(s)=\frac{1}{N} \sum_{n=0}^{N-1}\left|W_{n}(s)\right|$. 

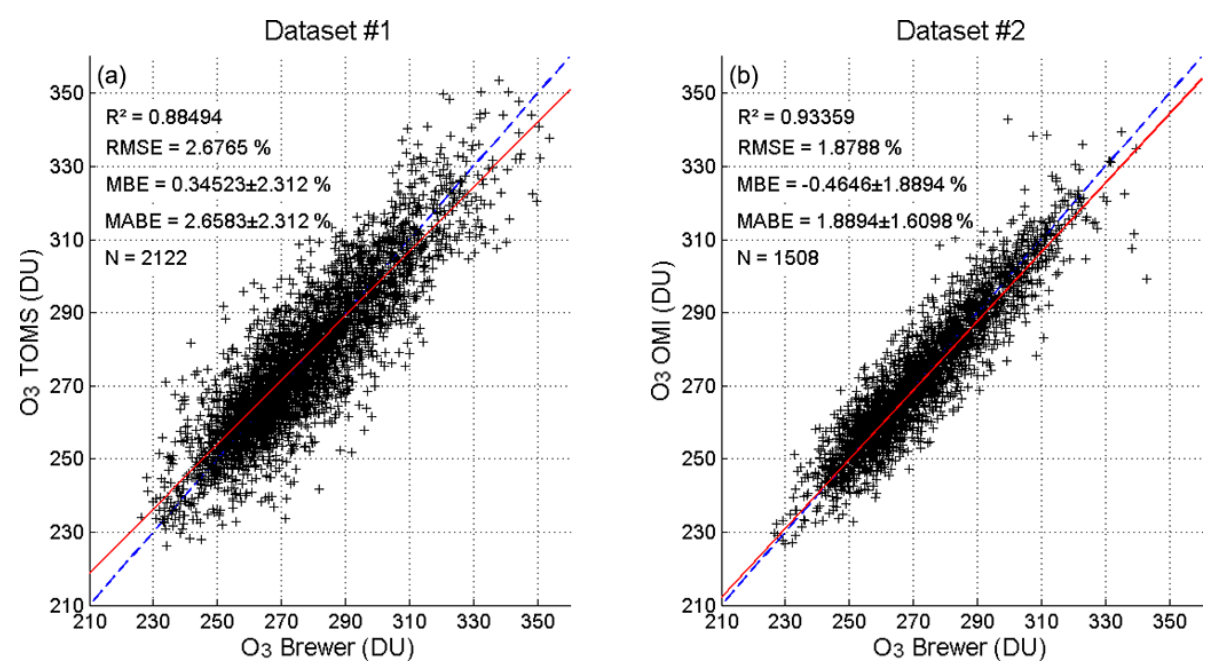

Figure 2. Scatterplot for the TOC in the region of the Southern Space Observatory obtained from the Brewer spectrophotometer and (a) TOMS (Dataset \#1) and (b) OMI (Dataset \#2) satellites. The dashed line (blue) represents the unit slope to which the data comply, and the solid line (red) is the regression line.

Possible errors in our finite-length time series at the beginning and the end of the wavelet power spectrum are minimized to pad the end of the time series with zeroes before doing the wavelet transform and then remove them afterward.

The region of the wavelet spectrum in which edge effects become important and are defined as the $e$-folding time for the autocorrelation of wavelet power at each scale is called the cone of influence (COI). The latter ensures that the edge effects are negligible beyond this point. In Figs. 5b and $6 \mathrm{~b}$, the region below the thin U-shaped curve indicates the COI, and the white dotted line represents the $95 \%$ confidence level. The wavelet power spectrum was normalized by $\left|W_{n}(s)\right|^{2} / \sigma^{2}$ to obtain a measure of the relative power for the Brewer and satellite TOC anomaly time series.

\section{Results and discussion}

\subsection{Daily and monthly analysis/comparisons}

The first step in the comparison study was to fit linear regression in the TOC values measured from the SSO between July 1992 and December 2014. Figure 2 shows the scatterplot plotted for Brewer spectrophotometer data and satellite data. The comparison was performed for Dataset \#1 (TOMS vs. Brewer) for the period from June 1992 to December 2005, containing 2122 data pairs (panel a), and Dataset \#2 (OMI vs. Brewer) between October 2004 and December 2014, with 1507 data pairs (panel b). The scatterplots in Fig. 2 reveal a high degree of proportionality between Brewer and both the TOMS (panel a) and OMI satellite (panel b), with high $R^{2}$ values of 0.88 and 0.93 , respectively. These results are similar to observed over the Canary Islands, Spain (Viatte et al., 2011; Antón et al., 2009, 2010a, b); Rome, Italy (Ialongo et al., 2008); and at other monitoring stations around the planet (Hendrick et al., 2011; Keckhut et al., 2010).

A small spread was observed in the datasets, with RMSE smaller than $3 \%$ in both datasets $(2.67 \%$ for Dataset \#1 and $1.87 \%$ for Dataset \#2). This is consistent with other similar studies carried out at the El Arenosillo station, where Brewer and satellite data have undergone this type of analysis (e.g., Antón et al., 2010b). The small values of the MBE index indicate a nonsignificant overestimation or underestimation of the values of TOC obtained through satellite instruments in relation to the Brewer spectrophotometer. However, it is observed that the TOMS satellite overestimates the Brewer instrument data for Dataset \#1 $(0.34 \pm 2.31 \%)$, and the OMI satellite underestimates the Brewer instrument Dataset \#2 $(-0.46 \pm 1.88 \%)$.

MABE values were observed to be reduced from $2.64 \pm 2.31 \%$ in Dataset \#1 to $1.88 \pm 1.61 \%$ in Dataset \#2, suggesting that the daily differences between Brewer and satellite data are small and are in better agreement with the measurement from the updated Brewer equipment. This is consistent with the results obtained by Antón et al. (2009, 2010a) in their study conducted for the Iberian Peninsula. This reduction, along with the reduced standard deviation, indicates that the spread between the datasets decreased due to launching more modern satellite instruments and the repair of the algorithms of the satellite instruments, performed over time (Bhartia and Wellemeyer, 2002), in addition to the substitutions of the ground equipment that occurred during these periods.

To verify the differences between the datasets, daily (top) and monthly (bottom) TOC mean comparison analysis were performed between ground-based and satellite instruments (see Fig. 3). In Fig. 3, the daily and monthly percent dif- 

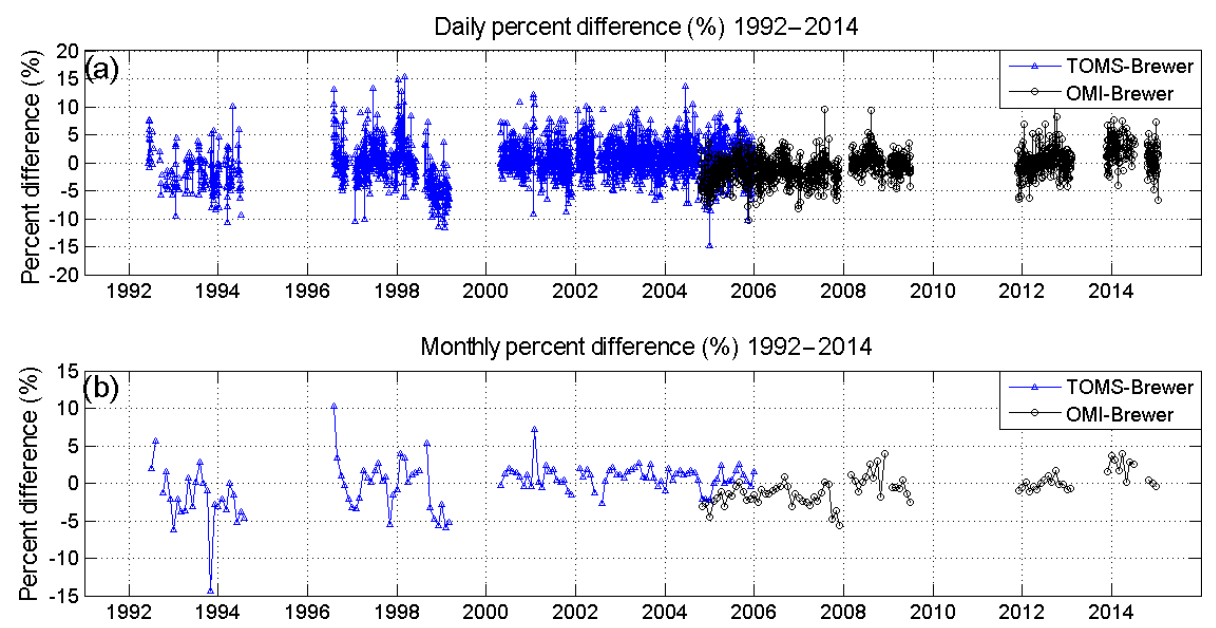

Figure 3. Top: time evolution of daily percentile differences between Brewer spectrophotometer and satellite instruments (with TOMS in blue and OMI in black). Bottom: time evolution of monthly percentile differences between Brewer spectrophotometer and satellite instruments (TOMS in blue and OMI in black). Both analyses the period between 1992 and 2014 for the Southern Space Observatory.

ferences between each dataset for the complete period between 1992 and 2014 are shown. The main observation here is a minor percent difference in Dataset \#1 with an average of $0.28 \pm 3.48 \%$, indicating a slight overestimation of the TOMS observations, and a strong decrease in performance is observed in the last operation period of the Brewer \#081 between 1998 and 1999. On the other hand, there were higher percentage differences for Dataset \#2, an average of $-0.50 \% \pm 2.44$, showing an underestimation of OMI with respect to the Brewer measurements. Similar results are also reported by Antón et al. $(2009,2010 b)$ for the Iberian Peninsula, where Brewer and OMI total ozone datasets were compared.

The analysis of the monthly percent differences between each different dataset highlights the periods of major differences observed in Fig. 3b, facilitating the identification of related reasons and these peaks in percentage differences, which are on average $-0.62 \pm 1.90$ for Dataset \#1 (TOMS Brewer) and $-0.03 \% \pm 2.88$ for Dataset \#2 (OMI - Brewer), showing an underestimation of the TOMS and OMI in the monthly dataset.

The end period of the Meteor-3 operation (1994) and the beginning of the operation of Earth Probe (1996) presented the most intense overestimation peak in percent differences observed during the studied period (1992-2014); however, the adjustment of the new correction algorithms solved the technical problems and stabilized the measures of the latter instrument (Wellemeyer et al., 2004).

Antón et al. (2010) noted that the period between 2000 and 2001 marked the beginning of the degradation of Earth Probe satellite measurements, coinciding with an overestimation peak observed during this period, when it was compared with Brewer \#056, which worked temporally in the SSO. The beginning of the operation of Brewer \#167 and the end of the operation period of the Earth Probe satellite instrument were characterized by weak underestimation peaks observed in 2004. The same behavior was observed at the beginning of the operation of the OMI satellite instrument when it was compared with Brewer \#167 during this period.

The results presented above confirm the effectiveness of the Brewer spectrophotometer measures on the SSO, enabling their use in studies of climatology and seasonal and interannual variability performed in the next section.

\subsection{TOC temporal variability at SSO}

\subsubsection{Climatology and seasonal TOC variation}

The annual cycle is a major component of long-term TOC variation at middle latitudes, and it can be controlled by a balance between transport associated with the diabatic circulation of the stratosphere or the Brewer-Dobson circulation and photochemical loss (Tung and Yang, 1988), and this cycle can be clearly identified in the TOC time series (Fig. 1) of the SSO between 1992 and 2014 for both ground-based and satellite instruments.

For the purpose of this work, the ozone climatology and its seasonal variability at the SSO were calculated. The monthly mean ozone values were obtained by grouping the daily TOC data in terms of the month and irrespective of the year and subjecting it to qualitative analysis (i.e., within $\pm 2 \mathrm{SD}$ ); hence, the data have better accuracy and have a limited contribution from the extreme events. This method is similar to the one employed by Sivakumar et al. (2007) in their study of the climatology and variability in the stratospheric ozone over Réunion, France.

In this study, a seasonal variation with higher values in spring and lower values in autumn of each year and $274.4 \pm 19.7 \mathrm{DU}$ as the Brewer TOC average value in the 


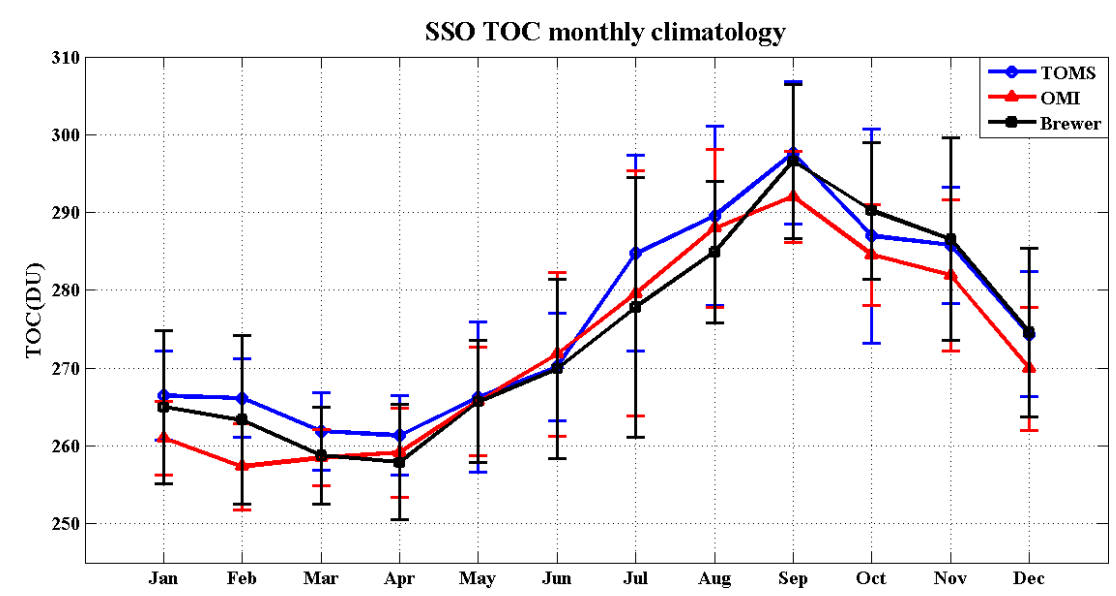

Figure 4. TOC monthly climatology means for the period between 1992 and 2014 by Brewer spectrophotometer (black) and TOMS (blue) and OMI (red) satellite instruments over Southern Space Observatory (SSO) regions.

region of the Southern Space Observatory were observed. The TOC monthly climatology evolution is shown together with standard deviation from the Brewer spectrophotometer (black) and TOMS (blue) and OMI (red) satellite instruments where an annual oscillation is observed, as shown in Fig. 4.

In the midlatitude regions, during winter and early spring, the transportation associated with the Brewer-Dobson stratosphere circulation is causing the build-up of ozone, culminating with its maximum in springtime (London, 1985). However, during the late spring and summer there is a decline in ozone caused by transportation decrease, and photochemical loss dominates with the increase in solar radiation (Tung and Yang, 1988).

Both Brewer and satellite instruments present similar climatological behaviors, with clear ozone seasonal cycles, having a minimum $(\sim 260 \mathrm{DU})$ in April and a maximum ( $\sim 295$ DU) in September with an amplitude of 35 DU. This is in agreement with the results obtained for midlatitude regions by Antón et al. (2011) over Portugal, Zou et al. (2000) over Tibet, and Brinksma et al. (1998) over Lauder in New Zealand

The SSO geographical location is close to the dynamic barriers, and it is thus expected to show high TOC variability due to dynamic processes such as stratospheretroposphere exchanges and meridian exchanges between the stratospheric tropical reservoir and midlatitudes (Baray et al., 1999; Portafaix et al., 2003) or between the Antarctic ozone hole and midlatitudes (Kirchhoff et al., 1996).

\subsubsection{Interannual TOC variability}

The main modes of interannual TOC variability over SSO between 1992 and 2014 were analyzed by applying the wavelet transform method to the Brewer and satellite TOC monthly anomaly time series. The time series used for the wavelet analysis on the SSO between 1992 and 2014 (panel a), the normalized wavelet spectrum (panel b) and the obtained global wavelet spectrum (panel c) are presented in Figs. 5 (Brewer) and 6 (satellite). It is clearly highlighted in these figures that the largest intensities found in the power spectrum over the south of Brazil TOC are concentrated within a QBO variation with a 22- and 34-month band (Baldwin et al., 2001), El Niño-Southern Oscillation (ENSO) variation with a 24-96-month band (Trenberth, 1976; Reid, 1994) and the 11-year solar cycle variations (Lee and Smith, 2003). These results indicate that the observed modes are present in the interannual TOC variability recorded between 1992 and 2014 over the SSO by Brewer spectrophotometer and Satellite instruments (TOMS and OMI).

We observed periodicities in the normalized wavelet spectrum in the 22- to 34-month bands in two different periods. The first period between 1995 and 2000 and the second period between 2004 and 2009 were more intense in the Brewer dataset (Fig. 5) than the satellite dataset (Fig. 6). These periodicities are linked to the QBO signal, which could confirm the QBO influence as the main ozone variability observed over the SSO because both are within the $95 \%$ significance level contours (white contours), with a peak in the global wavelet spectrum inside the $95 \%$ confidence spectrum. Periodicities in the 24-96-month band were also observed in two different periods. The first is observed between 1993 and 2009 within the $95 \%$ significance level contours, and the second period in 2011 is outside the $95 \%$ significance level contours. The peak associated with this mode of TOC variability and present in the global wavelet spectrum is outside the $95 \%$ confidence spectrum for the case of the Brewer dataset. For satellite dataset, this periodicity is weaker and also outside the $95 \%$ of significance level contours and the cone of influence. This periodicity probably indicates the ENSO signature on the TOC over the SSO station. Furthermore, periodicity in the 11-year band, related to the influence of 11year solar cycle, was observed in the whole period outside the cone of influence and $95 \%$ significance level contours in 

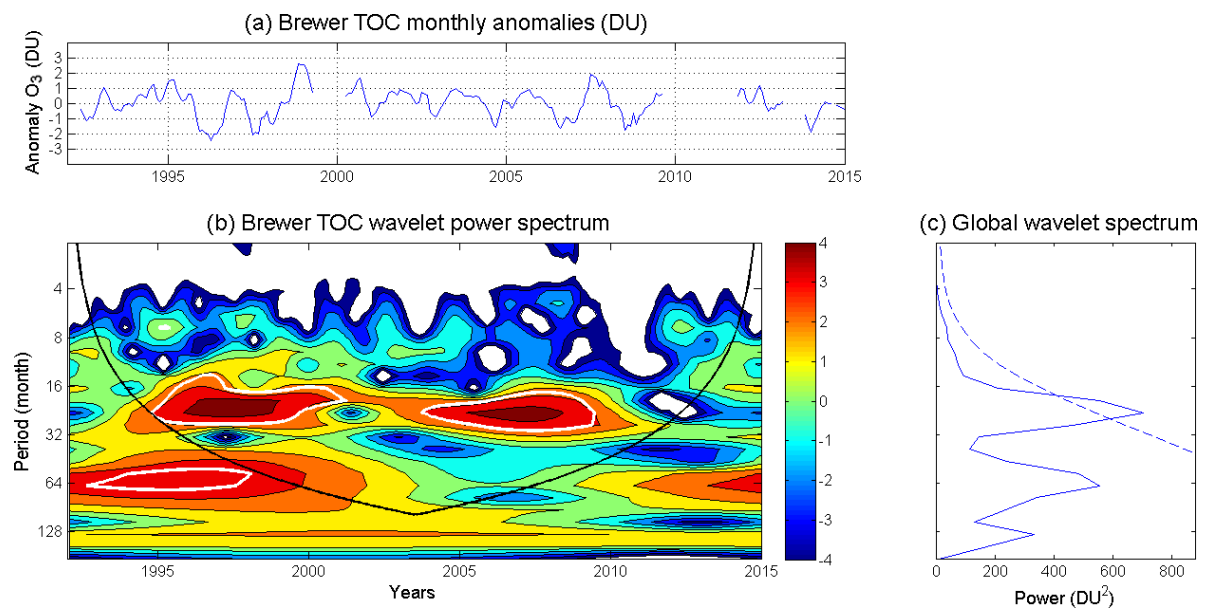

Figure 5. (a) The Brewer TOC monthly anomaly time series used for the wavelet analysis over Southern Space Observatory between 1992 and 2014. (b) The wavelet power spectrum of (a) using the Morlet wavelet, normalized by $1 / \sigma^{2}$. The left axis is the Fourier period (in month), the power wavelet scale is on the right axis, and the bottom axis is time (year). The white contour encloses regions of greater than the $95 \%$ confidence level and the U-shaped curve indicates the cone of influence. (c) The global wavelet spectrum of (a), where the dashed line is the $95 \%$ confidence spectrum.
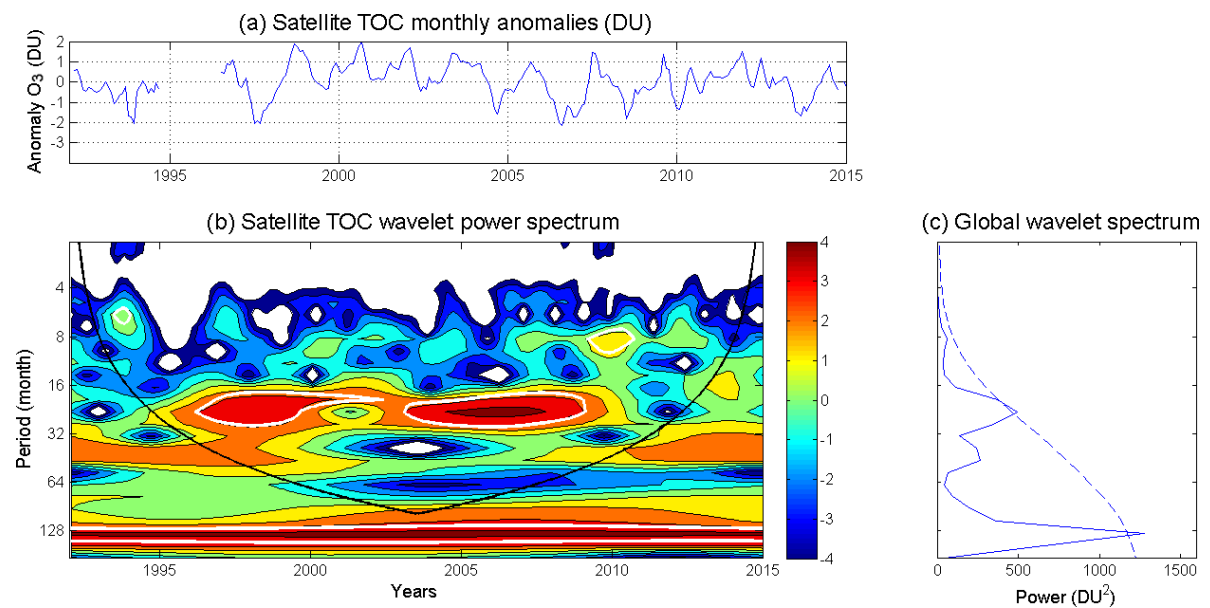

Figure 6. (a) The satellite TOC monthly anomaly time series used for the wavelet analysis over Southern Space Observatory between 1992 and 2014. (b) The wavelet power spectrum of (a) using the Morlet wavelet, normalized by $1 / \sigma^{2}$. The left axis is the Fourier period (in month), the power wavelet scale is on the right axis, and the bottom axis is time (year). The white contour encloses regions of greater than $95 \%$ confidence level and the U-shaped curve indicates the cone of influence. (c) The global wavelet spectrum of (a), where the dashed line is the $95 \%$ confidence spectrum.

normalized wavelet spectrum and outside of the $95 \%$ confidence level in the global wavelet spectrum in the Brewer dataset and inside the $95 \%$ significance level contours in the normalized wavelet spectrum and global wavelet spectrum in the satellite dataset, probably caused by radiometric calibration in solar radiation incident and backscattered ultraviolet sunlight measures (McPeters et al., 1998).

These results indicate the QBO influence as the main mode of TOC interannual variability over the SSO for having the largest intensities within the level of $95 \%$ significance for contours and cone of influence in the normalized wavelet spectrum with a peak in the global wavelet spectrum, which is inside the $95 \%$ confidence spectrum. These results are in accordance with results obtained by Rigozo et al. (2012) in a local reconstructed daily ozone time series over the south of Brazil. In other midlatitude regions, similar results were observed in SAGE II data by singular value decomposition (Randel and Wu, 1996; Fioletov at al., 2006), TOMS data by Yang and Tung (1994), MLS satellite ozone profile by wavelets analyses (Fadnavis and Beig, 2008). In addition, numerical studies in general circulation models (Chipperfield et al., 1994; Takahashi, 1999) found the ozone anomaly in midlatitude regions in approximately opposite phase in comparison with the QBO index. 


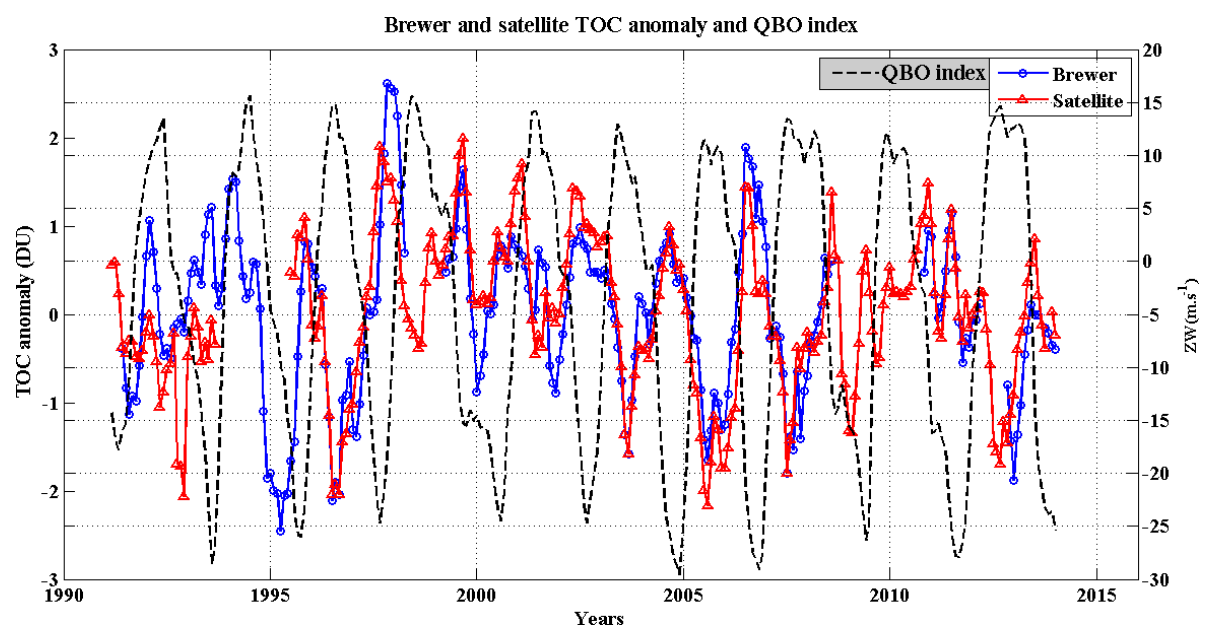

Figure 7. TOC monthly anomaly time series by Brewer spectrophotometer (blue) and satellite instruments (red) over the Southern Space Observatory compared with the QBO index (dashed line) between 1992 and 2014.

A positive temperature gradient (pole to Equator) produces an increase in westerly winds with height (positive wind shear) and the consequent slowing of Brewer-Dobson circulation, while a negative temperature gradient (Equator to pole) produces increasing easterly winds with height (negative wind shear) and the consequent speeding up of BrewerDobson circulation, balanced in the subtropics for the socalled QBO-induced meridional circulation, forced by the dissipation of vertically planetary waves propagating like Rossby and gravity (Holton and Tan, 1980; Bowman, 1989; O'Sullivan and Salby, 1990).

The deceleration of the Brewer-Dobson circulation produces a slow reduction in the upward air motion and positive ozone anomaly in the tropics by production accumulation. This is accompanied by a reduction in ozone transport to the midlatitudes, causing negative ozone anomaly in this region. This condition is associated with positive anomalies of the equatorial zonal wind (Reed et al., 1961; Reid and Cage, 1985). The reverse behavior of the enhanced Brewer-Dobson circulation, associated with negative anomalies of the equatorial zonal wind QBO, causes the acceleration in upward air motion in the tropics and the consecutive negative ozone anomaly by greater removal and transport to midlatitudes, where the positive ozone anomaly is observed for bringing air rich in ozone from the tropical stratosphere.

Figure 7 presents the anomaly TOC time series obtained from the Brewer spectrophotometer (blue) and satellite (TOMS - OMI) observations (red). The black dotted line is the monthly zonal wind at $30 \mathrm{hPa}$ over Singapore, which is used in this present work as the QBO index. It is apparent in Fig. 7 that the variability in TOC monthly anomaly over SSO is in quasi-anti-phase with the QBO modulation, and the amplitude of TOC anomaly is in the 6DU range and in accordance with the above explanation. These results are consistent with those found in other midlatitude regions as observed in global satellite data (Randel and Wu, 1996; Yang and Tung, 1994; Baldwin, 2001) or in individual station as over the Tibetan Plateau (Zou et al., 2000) and over Lauder on New Zealand (Brinksma et al., 1998).

ENSO and 11 years of solar cycle modulations do not show a statistical significance in relation to the TOC monthly anomaly time series signal. This indicates a need for a specific and detailed investigation in relation to these action modes into the interannual and interdecadal variability in TOC over the SSO. Moreover, the quantification of variability explanation for each mode, trend studies, and analysis regarding the influence of the Antarctic ozone hole over the south of Brazil can be performed using the long-term well-adjusted measures of the Brewer spectrophotometer and TOMS and OMI satellites over the SSO region.

\section{Conclusion}

This study shows the TOC measurement of the Southern Space Observatory $\left(29.26^{\circ} \mathrm{S}, 53.48^{\circ}\right.$ and $488 \mathrm{~m}$ altitude), Brazil, for a quasi-continuous period of 23 years (19922014) by three successive Brewer spectrophotometers (\#081, $\# 056$ and \#167). These Brewer measurements were compared to daily and monthly observations of spaceborne satellite sensor data from TOMS and OMI and were in excellent agreement. Moreover, this study highlights the scientific significance in contributing to the understanding of the seasonal and interannual ozone variability over southern Brazil once the monthly climatology determined that the seasonal TOC variation is dominated by the annual cycle, and the wavelet analysis applied in the SSO TOC anomaly time series determined that the $\mathrm{QBO}$ is the main mode of interannual variability complementing studies on the global and regional scales. Additionally, the comparison between the SSO TOC 
anomaly time series with the QBO index has revealed that the two are approximately in opposite phases.

The excellent agreement between simultaneous Brewer and satellite measurements of TOMS (Meteor-3 and Earth Probe) and OMI was verified by high $R^{2}$ values ( 0.88 and 0.93 , respectively) and a small spread in both datasets, with RMSE smaller than 3\% (2.67\% for Dataset \#1 and $1.87 \%$ for Dataset \#2). The MBE parameter indicates that the TOMS satellite overestimates the Brewer instrument, and the OMI satellite underestimates the Brewer instrument in daily analyses; the reduction in the MABE values and their standard deviation between Brewer and satellite show a better agreement with the update in the measurement equipment. The percentage differences between the Brewer and satellite datasets show that, on average, the satellite instrument TOMS overestimates the Brewer data $(0.28 \pm 2.43 \%)$ and that the OMI satellite instrument underestimates the Brewer data by $-0.5 \pm 2.44 \%$. Periods near equipment exchange present a higher percent difference in peaks, highlighted by observed monthly analysis differences, as in the beginning of the Earth Probe operation or the end of the operation of Brewer spectrophotometer \#081. These results confirm the effectiveness of the long-term Brewer spectrophotometers' measurements over the SSO since there is no major discrepancy between the datasets, maintaining the differences within the $\pm 5 \%$ range.

The annual cycle is the dominant mode in the seasonal TOC variation, associated with the Brewer-Dobson circulation and photochemical loss variability, with a minimum $\sim 260$ DU in spring (April) and a maximum $\sim 295 \mathrm{DU}$ in autumn (September) and amplitude of $35 \mathrm{DU}$, consistent with the obtained results in other midlatitude sites. The main modes of interannual TOC variability were analyzed, based on wavelet transform, and the obtained results highlighted the presence of variation within the 22-34-month band associated with QBO modulation, the variation within 24-96month band associated with ENSO modulation, and variations in the 11-year band associated with the 11-year solar cycle modulation in both ground-based and satellite datasets. However, only the QBO modulation was within the level of $95 \%$ significance level contours, and the cone of influence (COI) in the normalized wavelet spectrum and the global wavelet spectrum in both the ground-based and satellite datasets indicate the QBO influence as the main mode of interannual variability in the Brewer and satellite TOC monthly anomalies in the SSO time series. The association of variations in the SSO Brewer and satellite TOC monthly anomaly with the equatorial zonal wind QBO index was verified and observed that the Brewer and satellite TOC are in quasi-anti-phase with the QBO modulation and have mean TOC anomaly amplitude of $6 \mathrm{DU}$.

The verification of ENSO and 11 year solar cycle modulations requiring specific and detailed investigation in relation to these action modes into the interannual and interdecadal variability in TOC over the SSO, together with the quantify- ing of variability explanation for each mode, trend analyses and the Influence of the Antarctic ozone hole over the south of Brazil studies, next goals for this long-term Brewer spectrophotometer and satellite TOMS and OMI measurements at the Southern Space Observatory.

\section{Data availability}

The data are not yet available from international networks and need to be extracted from individual plans. For further information contact the corresponding author.

Author contributions. Lucas Vaz Peres is the principal investigator of the present study; Damaris Kirsch Pinheiro was the supervisor and Hassan Bencherif and Vagner Anabor the cosupervisors of his doctoral degree, and all participated in interpretation of the results. In addition to that, they are coordinators of the National Institute for Space Research (INPE). Neusa Maria Paes Leme, José Valentin Bageston, and Nelson Jorge Schuch provided the Brewer spectrophotometer data and contributed to the review of manuscript. Nelson Bègue, Nkanyiso Mbatha, André Passaglia Schuch, Abdoulwahab Mohamed Toihir, and Thierry Portafaix contributed to data analysis and the review of the manuscript.

Acknowledgements. This work is part of the Graduate Program in Meteorology, Federal University of Santa Maria (UFSM), together with the Laboratory of Atmosphere and Cyclones (LACy) of the University of Reunion Island (France), supported by Coordination for the Improvement of Higher Education Personnel (CAPES) Process no. 99999.010629/2014-09 and the National Institute of Science and Technology - Antarctic Environmental Research (INCT-APA), which receives scientific and financial support of the National Council for Scientific and Technological Development (CNPq process: no. 574018/2008-5) and the Carlos Chagas Filho Foundation for Research Support in the State of Rio de Janeiro (FAPERJ No. E-16/170 023/2008). The authors also acknowledge the support of the Ministry of Science, Technology and Innovation (MCTI), the Ministry of Environment (MMA), and the Inter-ministerial Commission for Sea Resources (CIRM) along with the Research Support Foundation of the Rio Grande do Sul State (FAPERGS) by scholarship, as well as the NASA/TOMS/OMI and NOAA climate index for the data used in the analysis, the ATMANTAR Project, and the MCTI/CNPq announcement of International Polar Year, Case No. 52.0182/2006-5.

The topical editor, A. J. Kavanagh, thanks two anonymous referees for help in evaluating this paper.

\section{References}

Angell, J. K. and Korshover, J.: Quasi-biennial variations in temperature, total ozone, and tropopause height, J. Atmos. Sci., 21, 479-492, 1964. 
Antón, M., López, M., Vilaplana, J. M., Kroon, M., McPeters, R., Bañón, M., and Serrano, A.: Validation of OMI-TOMS and OMIDOAS total ozone column using five Brewer spectroradiometers at the Iberian Peninsula, J. Geophys. Res.-Atmos., 114, D14307, doi:10.1029/2009JD012003, 2009.

Antón, M., Cachorro, V. E., Vilaplana, J. M., Toledano, C., Krotkov, N. A., Arola, A., Serrano, A., and de la Morena, B.: Comparison of UV irradiances from Aura/Ozone Monitoring Instrument (OMI) with Brewer measurements at El Arenosillo (Spain) Part 1: Analysis of parameter influence, Atmos. Chem. Phys., 10, 5979-5989, doi:10.5194/acp-10-5979-2010, 2010a.

Antón, M., Vilaplana, J. M., Kroon, M., Serrano, A., Parias, M., Cancillo, M. L., and De la Morena, B. A.: The Empirically Corrected EP-TOMS Total Ozone Data Against Brewer Measurements at El Arenosillo (Southwestern Spain), IEEE T. Geosci. Remote Sens., 48, 7, 3039-3045, doi:10.1109/TGRS.2010.2043257, 2010 b.

Antón, M., Bortoli, D., Costa, M. J., Kulkarni, P. S., Domingues, A. F., Barriopedro D., Serrano, A., and Silva, A. M.: Temporal and spatial variabilities of total ozone column over Portugal, Remote Sens. Environ., 115, 855-863, doi:10.1016/j.rse.2010.11.013, 2011.

Baldwin, M. P., Gray, L. J., Dunkerton, T. J., Hamilton, K., Haynes, P. H., Randel, W. J., Holton, J. R., Alexander, M. J., Hirota, I., Horinouchi, T., Jones, D. B. A., Kennersley, J. S., Marquardt, C., Sato, K., and Takahashi, M.: The quasi-biennial oscillation, Rev. Geophys., 39, 179-229, doi:10.1029/1999RG000073, 2001.

Balis, D., Koukouli, M. E., Brinksma, E. J., Kroon, M., Veefkind, J. P., Labow, G., and McPeters, R. D.: Validation of Ozone Monitoring Instrument total ozone column measurements using Brewer and Dobson spectrophotometer groundbased observations, J. Geophys. Res.-Atmos., 112, D24S46, doi:10.1029/2007JD008796, 2007.

Baliunas, S., Frick, P., Sokoloff, D., and Soon, W.: Time scales and trends in the central England temperature data (1659-1990): A wavelet analysis, Geophys. Res. Lett., 24, 1351-1354, 1997.

Baray, J. L., Leveau, J., Porteneuve, J., Ancellet, G., Keckhut, P., Posny, F., and Baldy, S.: Description and evaluation of the tropospheric ozone lidar implemented on an existing lidar in the southern subtropics, Appl. Optics, 33, 6808-6817, doi:10.1364/AO.38.006808,1999.

Bhartia, P. K. and Wellemeyer, C.: TOMS-V8 total $\mathrm{O}_{3}$ algorithm, in: OMI Algorithm Theoretical Basis Document, edited by: Bhartia, P. K., Vol. II, Greenbelt, MD: NASA Goddard Space Flight Cent., 15-31, OMI Ozone Products, ATBD-OMI-02, available at: http://projects.knmi.nl/omi/documents/data/OMI_ ATBD_Volume_2_V2.pdf (last access: 27 December 2016), 2002.

Bowman, K. P.: Global patterns of the quasi-biennial oscillation in total ozone, J. Atmos. Sci., 46, 3328-3343, 1989.

Brinksma, E. J., Meijer, Y. J., Connor, B. J., Manney, G. L., Bergwerff, J. B., Bodeker, G. E., Boyd, I. S., Liley, J. B., Hogervorst, W., Hovenier, J. W., Livesey, N. J., and Swart, D. P. J.: Analysis of record-low ozone values during the 1997 winter over Lauder, New Zealand, Geophys. Res. Lett., 25, 2785-2788, doi:10.1029/98GL52218, 1998.

Chipperfield, M. P., Cariolle, D., and Simon, P.: A 3-D chemical transport model study of chlorine activation during EASOE,
Geophys. Res. Lett., 21, 1467-1470, doi:10.1029/93GL01678, 1994.

Daubechies, I.: Ten Lectures on Wavelets, Society for Industrial and Applied Mathematics, 357 pp., 1992.

De Laat, A. T. J., Van Der A, R. J., Allaart, M. A. F., Van Weele, M., Benitez, G. C., Casiccia, C., Leme, N. M. P., Quel, E., Salvador, J., and Wolfram, E.: Extreme sunbathing: Three weeks of small total O-3 columns and high UV radiation over the southern tip of South America during the 2009 Antarctic O-3 hole season, Geophys. Res. Lett., 37, L14805, doi:10.1029/2010GL043699, 2010.

Dobson, G. M. B.: Observations of the amount of ozone in the Earth's atmosphere and its relation to other geophysical conditions, P. Roy. Soc. Lond. A., 129, 411-433, 1930.

Dobson, G. M. B.: Forty years' research on atmospheric ozone at Oxford: A history, Appl. Optics, 7, 387-405, 1968.

Fadnavis, S. and Beig, G.: Spatiotemporal variation of the ozone QBO in MLS data by wavelet analysis, Ann. Geophys., 26, 3719-3730, doi:10.5194/angeo-26-3719-2008, 2008.

Farman, J. C., Gardiner, B. G., and Shanklin, J. D.: Large losses of total ozone in Antarctica reveal seasonal $\mathrm{ClO}_{x} / \mathrm{NO}_{x}$ interaction, Nature, 315, 207-210, 1985.

Fioletov, V. E.: Ozone Climatology, Trends, and Substances that Control Ozone, Atmos. Ocean, 46, 39-67, doi:10.3137/ao.460103, 2008.

Fioletov, V. E., Bodeker, G. E., Miller, A. J., McPeters, R. D., and Stolarski, R.: Global and zonal total ozone variations estimated fromground-based and satellitemeasurements: 19642000, J. Geophys. Res., 107, 4647, doi:10.1029/2001JD001350, 2002.

Fioletov, V. E., Kerr, J. B., McElroy, C. T., Wardle, D. I., Savastiouk, V., and Grajnar, T. S.: The Brewer reference triad, Geophys. Res. Lett., 32, L20805, doi:10.1029/2005GL024244, 2005.

Fioletov, V. E., Tarasick, D. W., and Petropavlovskikh, I.: Estimating ozone variability and instrument uncertainties from SBUV(/2), ozonesonde, Umkehr, and SAGE II measurements: Shortterm variations, J. Geophys. Res., 111, D02305, doi:10.1029/2005JD006340, 2006.

Foufoula-Georgiou, E. and Kumar, P.: Wavelets in Geophysics, Academic Press, 373 pp., 1995.

Hadjinicolaou, P., Pyle, J. A., and Harris, N. R. P.: The recent turnaround in stratospheric ozone over northern middle latitudes: A dynamical modeling perspective, Geophys. Res. Lett., 32, L12821, doi:10.1029/2005GL022476, 2005.

Hase, F., Blumenstock, T., and Paton-Walsh, C.: Analysis of the instrumental line shape of high-resolution Fourier transform IR spectrometers with gas cell measurements and new retrieval software, Appl. Optics, 38, 3417-3422, doi:10.1364/AO.38.003417, 1999.

Herman, J. R., Bhartia, P. K., Krueger, A. J., McPeters, R. D., Wellemeyer, C. G., Seftor, C. J., Jaross, G., Schlesinger, B. M., Torres, O., Labow, G., Byerly, W., Taylor, S. L., Swissler, T., Cebula, R. P., and Gu, X. Y.: Meteor-3 Total Ozone Mapping Spectrometer (TOMS) Data Products User's Guide, NASA, Washington, DC, Tech. Rep. 1996.

Hendrick, F., Pommereau, J.-P., Goutail, F., Evans, R. D., Ionov, D., Pazmino, A., Kyrö, E., Held, G., Eriksen, P., Dorokhov, V., Gil, M., and Van Roozendael, M.: NDACC/SAOZ UV-visible total ozone measurements: improved retrieval and comparison 
with correlative ground-based and satellite observations, Atmos. Chem. Phys., 11, 5975-5995, doi:10.5194/acp-11-5975-2011, 2011.

Holton, J. R. and Lindzen, R. S.: An updated theory for the quasibiennial cycle of the tropical stratosphere, J. Atmos. Sci., 29, 1076-1080, 1972.

Holton, J. R. and Tan, H.-C.: The influence of the equatorial quasibiennial oscillation on the global circulation at $50 \mathrm{mb}$, J. Atmos. Sci., 37, 2200-2208, 1980.

Holton, J. R., Haynes, P. H., Mcintyre, M. E., Douglass, A. R., Rood, R. B., and Pfister, L.: Stratosphere-troposphere Exchange, Rev. Geophys., 3, 403-439, 1995.

Hudson, R. D., Andrade, M. F., Follette, M. B., and Frolov, A. D.: The total ozone field separated into meteorological regimes Part II: Northern Hemisphere mid-latitude total ozone trends, Atmos. Chem. Phys., 6, 5183-5191, doi:10.5194/acp-6-5183-2006, 2006.

Ialongo, I., Casale, G. R., and Siani, A. M.: Comparison of total ozone and erythemal UV data from OMI with ground-based measurements at Rome station, Atmos. Chem. Phys., 8, 3283-3289, doi:10.5194/acp-8-3283-2008, 2008.

Keckhut, P., Hauchecorne, A., Blanot, L., Hocke, K., GodinBeekmann, S., Bertaux, J.-L., Barrot, G., Kyrölä, E., van Gijsel, J. A. E., and Pazmino, A.: Mid-latitude ozone monitoring with the GOMOS-ENVISAT experiment version 5: the noise issue, Atmos. Chem. Phys., 10, 11839-11849, doi:10.5194/acp10-11839-2010, 2010.

Kerr, J. B.: New methodology for deriving total ozone and other atmospheric variables from Brewer spectrometer direct Sun spectra, J. Geophys. Res., 107, 4731, doi:10.1029/2001JD001227, 2002.

Kerr, J. B., McElroy, C. T., Wardle, D. I., Olafson, R. A., and Evans, W. F.: The automated Brewer Spectrophotometer, Proc. Quadr. Ozone Symp., edited by: Halkidiki, C., Zerefos, S., and Ghazi, A., D. Reidel, Norwell, Mass., 396-401, 1985.

Kirchhoff, V. W. J. H., Schuch, N. J., Pinheiro, D. K., and Harris, J. M.: Evidence for an ozone hole perturbation at $30^{\circ}$ south, Atmos. Environ., 30, 1481-1488, doi:10.1016/1352-2310(95)00362-2, 1996.

Lee, H. and Smith, A. K.: Simulation of the combined effects of soalr cycle, quasi-biennial oscillation and volcanic forcing on stratospheric ozone changes in recent decades, J. Geophys. Res., 108, D24049, doi:10.1029/2001JD001503, 2003.

London, J.: Observed distribution of atmospheric ozone and its variations, in: Ozone in the free atmosphere, edited by: Whitten, R. C. and Prasad, S. S., New York: Van Nostrand Reinhold, 1, 1180, 1985.

McPeters, R. D., Bhartia, P. K., Krueger, A. J., Herman, J. R., Schlesinger, B. M., Wellemeyer, C. G., Seftor, C. J., Jaross, G., Taylor, S. L., Swissler, T., Torres, O., Labow, G., Byerly, W., and Cebula, R. P.: Nimbus-7 Total Ozone Mapping Spectrometer (TOMS) Data Products User's Guide, NASA, Washington, DC, Tech. Rep., 1996.

McPeters, R. D., Bhartia, P. K., Krueger, A. J., Herman, J. R., Wellemeyer, C. G., Seflor, G., Jaross, C. F., Torres, O., Moy, L., Abow, G., Byerly, W., Taylor, S. L., Swisler, T., and Cebula, R. P.: Earth Probe Total Ozone Mapping Spectrometer (TOMS) data products user guide, NASA, Washington, DC, Tech. Rep. TP-1998206895, 1998.
O'Sullivan, D. and Salby, M. L.: Coupling of the quasi-biennial oscillation and the extra-tropical circulation in the stratosphere through planetary wave transport, J. Armos. Sci., 47, 650-673, 1990.

Percival, D. P.: On estimation of the wavelet variance, Biometrika, 82, 619-631, 1995.

Perez, A., de Carcer, I. A., Tocho, J. O., Crino, E., Sandoval, H. F. R., Berni, M. E., Da Silva, L., Henriques, D., Cusso, F., and Jaque, F.: The extent of the ozone hole over South America during the spring of 1993, 1994, and 1995, J. Phys. D Appl. Phys., 31, 812-819, 1998.

Pinheiro, D. K., Peres, L. V., Crespo, N. M., Schuch, N. J., and Leme, N. M. P.: Influence of the Antarctic ozone hole over South of Brazil in 2010 and 2011, Annual Active Report 2011 - National Institute of Science and Technology Antarctic Environmental Research, 1, 34-38, doi:10.4322/apa.2014.058, 2012.

Pommereau, J.-P. and Goutail, F.: $\mathrm{O}_{3}$ and $\mathrm{NO}_{2}$ ground-based measurements by visible spectrometry during arctic winter and spring 1988, Geophys. Res. Lett., 15, 891-894, doi:10.1029/GL015i008p00891, 1988.

Portafaix, T., Morel, B., Bencherif, H., Baldy, S., GodinBeekmann, S., and Hauchecorne, A.: Fine-scale study of a thick stratospheric ozone lamina at the edge of the southern subtropical barrier, J. Geophys. Res., 108, 4196, doi:10.1029/2002JD002741, 2003.

Randel, W. J. and Wu, F.: Isolation of the ozone QBO in SAGE II data by singular value decomposition, J. Atmos. Sci., 53, 25462559, 1996.

Reed, R. J., Campbell, W. J., Rasmussen, L. A., and Rogers, D. G.: Evidence of downward propagating annual wind reversal in the equatorial stratosphere, J. Geophys. Res., 66, 813-818, 1961.

Reid, G. C.: Seasonal and interannual temperature variations in the tropical stratosphere, J. Geophys. Res., 99, 18923-18932, 1994.

Reid, G. C. and Gage, K. S.: Inter-annual variations in the height of the tropical tropopause, J. Geophys. Res., 90, 5629-5635, 1985.

Reinsel, G. C., Weatherhead, E. C., Tiao, G. C., Miller, A. J., Nagatani, R. M., Wuebbles, D. J., and Flynn, L. E.: On detection of turnaround and recovery in trend for ozone, J. Geophys. Res., 107, ACH 1-1-ACH 1-12, doi:10.1029/2001JD000500, 2002.

Rigozo, N. R., Rosa, M. B. D., Rampelotto, P. H., Echer, M. P. D. S., Echer, E., Nordemann, Nordemann, D. J. R., Pinheiro, D. K., and Schuch, N. J.: Reconstruction and searching ozone data periodicities in southern Brazil $\left(29^{\circ} \mathrm{S}, 53^{\circ} \mathrm{W}\right)$, Brazilian Journal of Meteorology, 27, 243-252, 2012.

Semane, N., Teitelbaum, H., and Basdevant, C.: A very deep ozone minihole in the Northern Hemisphere stratosphere at midlatitudes during the winter of 2000, Tellus A, 54, 382-389, doi:10.1034/j.1600-0870.2002.01380.x, 2002.

Schuch, P. A., Santos, M. B., Lipinski, V. M., Peres, L. V, Santos C. P., Cechin S. Z., Schuch, N. J., Pinheiro, D. K., and Loreto, E. L. S.: Identification of influential events concerning the Antarctic ozone hole over southern Brazil and the biological effects induced by UVB and UVA radiation in an endemic treefrog species, Ecotox. Environ. Safe., 118, 190-198, doi:10.1016/j.ecoenv.2015.04.029, 2015.

SCI TEC: Brewer ozone spectrophotometer, Acceptance manual, Doc. AM-BA-C05-Rev C, SCI TEC Instruments, Seoul, 1988.

Sivakumar, V., Portafaix, T., Bencherif, H., Godin-Beekmann, S., and Baldy, S.: Stratospheric ozone climatology and variability over a southern subtropical site: Reunion Island $\left(21^{\circ} \mathrm{S}\right.$; 
55ํㅡ), Ann. Geophys., 25, 2321-2334, doi:10.5194/angeo-252321-2007, 2007.

Škerlak, B., Sprenger, M., and Wernli, H.: A global climatology of stratosphere-troposphere exchange using the ERA-Interim data set from 1979 to 2011, Atmos. Chem. Phys., 14, 913-937, doi:10.5194/acp-14-913-2014, 2014.

Solomon, S.: Stratospheric ozone depletion: a review of concepts and history, Rev. Geophys., 37, 275-316, doi:10.1029/1999RG900008, 1999.

SPARC Report No. 1: SPARC-IOC Assessment of Trends in the Vertical Distribution of Ozone, 1998.

Stohl, A., Wernli, H., Bourqui, M., Forster, C., James, P., Liniger, M. A., Seibert, P., and Sprenger, M.: A new perspective of stratosphere-troposphere exchange, B. Am. Meteorol. Soc., 84, 1565-1573, doi:10.1175/BAMS-84-11-1565, 2003.

Takahashi, M.: Simulation of the Quasi-Biennial Oscillation in a general circulation model, Geophys. Res. Lett., 26, 1307-1310, doi:10.1029/1999GL900188, 1999.

Thompson, A. M., Witte, J. C., McPeters, R. D., Oltmans, S. J., Schmidlin, F. J., Logan, J. A., Fujiwara, M., Kirchhoff, V. W. J. H., Posny, F., Coetzee, G. J. R., Hoegger, B., Kawakami, S., Ogawa, T., Johnson, B. J., Vömel, H., and Labow, G.: Southern Hemisphere Additional Ozonesondes (SHADOZ) 1998-2000 tropical ozone climatology 1. Comparison with Total Ozone Mapping Spectrometer (TOMS) and ground-based measurements, J. Geophys. Res., 108, 8238, doi:10.1029/2001JD000967, 2003.

Toihir, A. M., Bencherif, H., Sivakumar, V., El Amraoui, L., Portafaix, T., and Mbatha, N.: Comparison of total column ozone obtained by the IASI-MetOp satellite with ground-based and OMI satellite observations in the southern tropics and subtropics, Ann. Geophys., 33, 1135-1146, doi:10.5194/angeo-331135-2015, 2015.

Torrence, C. and Compo, G. P.: A practical guide to wavelet analysis, B. Am. Meteorol. Soc., 70, 61-78, doi:10.1175/15200477(1998)079<0061:APGTWA>2.0.CO;2, 1998.

Trenberth, K. E.: Spatial and temporal variations of the Southern Oscillation, Q. J. Roy. Meteor. Soc., 102, 639-653, 1976.

Tung, K. K. and Yang, H.: Dynamical component of seasonal and year-to-year changes in Antarctic and global ozone, J. Geophys. Res., 93, 12537-12559, doi:10.1029/JD093iD10p12537, 1988.
Vanicek, K.: Calibration history of the ozone spectrophotometers operated at the Solar and Ozone Observatory of CHMI in Hradec Kralove, Czech Republic, Publication of the Czech Hydrometeorological Institute, ISBN 80-86690-08-3, Prague, 2003.

Viatte, C., Schneider, M., Redondas, A., Hase, F., Eremenko, M., Chelin, P., Flaud, J.-M., Blumenstock, T., and Orphal, J.: Comparison of ground-based FTIR and Brewer $\mathrm{O}_{3}$ total column with data from two different IASI algorithms and from OMI and GOME-2 satellite instruments, Atmos. Meas. Tech., 4, 535-546, doi:10.5194/amt-4-535-2011, 2011.

Wang, B. and Wang, Y.: Temporal structure of the Southern Oscillation as revealed by waveform and wavelet analysis, J. Climate, 9, 1586-1598, doi:10.1175/15200442(1996)009<1586:TSOTSO>2.0.CO;2, 1996.

Wellemeyer, C. G., Taylor, S. L., Seftor, C. J., McPeters, R. D., and Bhartia, P. K.: A correction for the Total Ozone Mapping Spectrometer profile shape errors at high latitude, J. Geophys. Res., 102, 9029-9038, 1997.

Wellemeyer, C. G., Bhartia, P. K., McPeters, R. D., Taylor, S. L., and Ahn, Ch.: A new release of data from the Total Ozone Mapping Spectrometer (TOMS), available at: http: //www.sparc-climate.org/fileadmin/customer/6_Publications/ Newsletter_PDF/22_SPARCnewsletter_Jan2004.pdf, SPARC Newsletter, 22, 37-38, 2004.

World Meteorological Organization (WMO): Guide to Meteorological Instruments and Methods of Observation, 6th Edn., Geneva, Switzerland: WMO Publication \#8, 1996.

World Meteorological Organization (WMO): Comparison of Total Ozone Measurements of Dobson and Brewer Spectrophotometers and Recommended Transfer Functions (WMO TD No. 1147), prepared by: Staehelin, J., Kerr, J., Evans, R., and Vanicek, K., 2003.

Yang, H. and Tung, K. K.: Statistical significance and pattern of extratropical QBO in column ozone, Geophys. Res. Lett., 21, 22352238, doi:10.1029/94GL02120, 1994.

Zou, H., Chongping, J., and Libo, Z.: QBO signal in total ozone over Tibet, Adv. Atmos. Sci., 17, 562-568, doi:10.1007/s00376000-0019-4, 2000. 